\title{
Comentário VIII
}

\section{Maria Lucia Montes}

Departamento de Antropologia, Faculdade de Filosofia, Letras e Ciências Humanas/Universidade de São Paulo

Tomando como tema a História da Vida Privada, tal como se define seu perfil na publicação da série dos hoje famosos 5 volumes de mesmo título que começam a aparecer em 1985, o Prof. Vainfas faz, na verdade, um balanço das tendências recentes da historiografia francesa e das metamorfoses que, da Nova História, passando pela História das Mentalidades, hoje se abre sobre a História Cultural. Sua argumentação demonstra com clareza - e quer-me parecer ser esta a principal tese de seu artigo - que a vida privada, inteiramente ausente com seu nome próprio da obra que inaugura a Nova História, através do texto de abertura de Jacques le Goff a Faire de l'Histoire (1974), é, de fato, o "novo" campo ou "nicho" de investigação em que vêm desaguar os esforços e expectativas dos historiadores que se empenham em recriar essa outra História, passando sucessivamente, sob o impacto da crítica a que foram submetidos, por uma e outra de suas designações em moda. Esta é, sem dúvida, uma brilhante análise histórica das condiçōes de produção do conhecimento historiográfico recente na França.

Entretanto, não se restringe a isso a contribuição deste texto denso e rico de sugestões. Para além do viés específico do olhar de historiador, ao enfatizar questões de método e os próprios paradigmas da análise histórica, bem como os problemas de escala que nela se encontram envolvidos, a propósito da constituição da vida privada como objeto, problema, tema, abordagem ou campo de investigação, o autor repõe em debate a relação da História com o campo, objetos, problemas, temas e abordagens das Ciências do Homem, de 
cujo diálogo são filhas tanto a Nova História como a (velha) História das Mentalidades e a (nova) História Cultural, universos frente aos quais, ou no cruzamento dos quais, se procura situar o significado de uma História da Vida Privada. Daí porque um antropólogo possa ser chamado a comparecer ao debate que o texto suscita. Na plêiade de desafios com os quais ele nos confronta, um comentário deve necessariamente escolher pôr em evidência alguns temas e não outros, o que constitui uma tarefa dificil.

Diálogos, linhagens

Tratemos, em primeiro lugar, para estabelecer um contrapronto ao percurso do texto, de linhagens e, através delas, das diferentes formas de diálogo que se travam, e não apenas ao longo de uma história recente, entre a Antropologia e a História. Não por acaso, ao se referir às origens da História da Vida Privada, que antecedem de muito a publicação da obra coordenada por Georges Duby e Philippe Ariès, Vainfas recorre ao verbele Antropologia histórica de André Burguière no Dicionário das ciências históricas (1986), que recua ao século XVIII e início do XIX para recuperar a herança de Legrand d'Aussy e de sua Histoire de la vie privée des français (1782), ou a contribuição de A. Franklin, com sua obra la vie privée autrefois (1890): o primeiro reinvidica, em pleno Século das Luzes, e contra uma História voltada para os feitos de reis e generais, que a História se ocupe também do "burguês na sua vila, do camponês na sua cabana, do francês, enfim, no seio de sua família, com seus filhos", enquanto o segundo, herdeiro já do XIX, se propõe tratar de "moeurs, modes, usages des français du XVII au XVIIle siècle". Não é, pois, fortuito que esta filiação seja lembrada, associando o mundo da vida privada e sua história à Antropologia então nascente. De fato, o espírito antropológico, pelo menos em uma de suas vertentes na era da llustração, se cristaliza em um olhar que valoriza o trabalho do tempo e da história, sedimentado nos costumes, hábitos, crenças e valores em que se expressa o "espírito de um povo" e que compõem a especificidade de sua culfura. É deste modo que ele se opõe à pretensão iluminista que, na Revolução Francesa, se propõe a transformar essa herança por um ato de vontade, criando a virtude cívica que Robespierre requer dos cidadãos desse novo tempo de mudanças pela força de um exemplo suspenso à lâmina da guilhotina... O espírito de tolerância e o valor da diferença impregnam indefectivelmente um tal olhar.

$O$ interessante a notar, entretanto, é o fato de que, remontando no tempo o fio dessa linhagem, tanto Burguière quanto Vainfas associem imediatamente essa arqueologia da vida privada aos trabalhos clássicos de Braudel e Marc Bloch no início da Escola dos Annales, sem parecerem se dar conta de que, assim saltando por sobre o tempo e o espaço das filiações intelectuais, arriscam-se a deixar de prestar culto a outros e mais importantes heróis fundadores. Pois é Rousseau, talvez mais que legrand d'Aussy - o. Rousseau das Rêveries du promeneur solitaire, sem dúvida, mas também o Rousseau do Discurso sobre a origem da desigualdade, por exemplo, que Lévi-Strauss reconhece como - verdadeiro fundador da Antropologia (Lévi-Strauss: 1976) - quem deve ser invocado na origem dessa linhagem que desagua na História da Vida Privada. Ou, pelo menos, dessa História da Vida Privada que é proposta por Duby, que 
procura distinguila da banalidade da vida quotidiana - esta mesma que, na coleção da Hachette, publicada desde 1939, se esforça por "ressuscitar o passado, restituindo-lhe o sabor como se ai estivéssemos ainda" - bem como evitar que ela sucumba à tentação da intimidade da casa, da privacidade, do leito conjugal e do individualismo característicos do mundo moderno, marcado pelo surgimento e consolidação, entre os séculos XVI e XIX, do modelo conjugal da família burguesa, e cuja gênese é retraçada por Ariès na História social da criança e da familia. (Deixemos de lado, por enquanto, essa História Social como recorte analítico pertinente à compreensão de tais temas, bem como o problema do privado, da privacidade e do individualismo, que também se encontra no centro das reflexões tanto de Vainfas quanto dos autores cuja obra analisa, e ao qual retornaremos a seguir).

O que Duby propõe, portanto, ao procurar distinguir vida privada e vida quotidiana como objeto, tema ou campo de investigação, reivindicando para a análise da vida privada "um conceito mais ambicioso no enfoque, capaz de equilibrar descrição e explicação, olhares microscópicos e interpretações totalizantes" (Vainfas, p.12), é que a análise não se pulverize em detalhes esparsos, fragmentos da rotina do dia-a-dia, que resultam numa ."poatha de anedotas, de dados dispersos, de instantâneos, que nada têm a ver com o verdadeiro cotidiano e, ainda menos com a história", no dizer também de Jacques Le Goff, que nisso concorda com Duby. Ao contrário, para revelar seu verdadeiro valor, tais detalhes devem antes poder integrar-se "a uma análise dos sistemas históricos", a exemplo do trabalho de Marc Bloch ao buscar compreender as formas de sentir e de pensar em A sociedade feudal, que só ganham sentido quando relacionadas "a uma análise da sociedade feudal global". Da mesma forma, já antes o próprio Vainfas aproximara a obra de Legrand d'Aussy, basicamente centrada numa história da alimentação, seus produtos, suas técnicas e os comportamentos alimentares, da análise feita por Braudel das "estruturas do quotidiano", como parte do seu Civilisation matérielle, économie et capitalisme (1967), e que Burguière, por sua vez, compara ao trabalho de A. Franklin, no qual comparecem a história do vestuário, da moradia, da alimentação e dos ofícios - dimensões da vida social que, por constituírem fenômenos de longa duração, seriam consideradas por Braudel como mais determinantes da vida social do que as instituições políticas ou as práticas administrativas...

Em definitivo, o que se reconhece como característica desta linhagem - da arqueologia do século XVIII à História da Vida Privada, passando pela vida quotidiana, as mentalidades e a Nova História, para chegar enfim, e naturalmente, à herança da Escola dos Annales - é um certo olhar que recorta o social por uma perspectiva marcada pelo diálogo da História com a Sociologia e a Antropologia francesas em seu nascedouro, através da influência de Durkheim, Mauss e os demais membros do grupo ligado à publicação de L'Année sociologique. Retornar aos termos desse diálogo primitivo parece-me uma tarefa essencial para se avaliar de forma coerente as questões ligadas aos paradigmas e aos problemas de escala com os quais se confronta o Prof. Vainfas, ao analisar a historiografia francesa contemporânea à luz do debate sobre a História da Vida Privada. Dessa perspectiva, seria igualmente essencial retomar a brilhante análise 
de Norbert Elias em $O$ processo civilizador: uma história dos costumes lobra antiga, já que sua primeira publicação data de 1939), onde se distinguem com clareza as duas vertentes intelectuais que confluem, de forma nem sempre congruente, mas como diferentes versões de uma reflexão comum, para dar nascimento a uma problemática e um enfoque analítico que viriam a ser caracterizados como próprios da Antropologia: de um lado, a tradição alemã, centrada na noção de Kultur; de outro, a tradição francesa, baseada na idéia de civilisation.

Não é o caso de retomar aqui os meandros dessa trajetória. Basła lembrar, grosso modo, que enquanto uma vertente enfatiza a dimensão espiritual da vida dos agrupamentos humanos - traduzida nos seus hábitos, crenças, costumes, tradições musicais, de cantigas, versos e estórias que se transmitem através das gerações - com base em uma visão politicamente conservadora mas empiricamente realista da história, a outra se funda numa visão triunfalista do poder da razão - no que tange às conquistas materiais e ao domínio da natureza tanto quanto à organização da vida social - e que, portanto, faz ver a história real como o quadro de referência que confirma a dedução hipotética do triunfo da razão. Ambas as vertentes acabam, no entanto, por conciliar-se no século XIX, quando a tradição alemã soma ao sentido da história, que caracteriza a análise da cultura, a noção de progresso, apanágio do enfoque racionalista da marcha das civilizações. E sabemos o quanto a obra de um Hegel representa como fator decisivo nessa transformação. O que importa salientar, porém, é que, a partir de então, cultura e civilização podem tornar-se termos por assim dizer intercambiáveis para caracterizar as diferentes etapas do rumo inexorável da história, numa via de mão única que vai do inferior ao superior. Sob a égide desta história e o escrutínio de um Morgan, um Tylor, um Taylor, a vida dos agrupamentos humanos transforma-se então em objeto de um conhecimento totalizador, em que já não se separam crenças, costumes e formas de organização social, religião, leis e modalidades de poder político, família, domínio técnico sobre a natureza e modos sociais de sua apropriação. É assim que, pela primeira vez, torna-se possível conceber como objetos de um saber específico o homem e a sociedade, como nos demonstrou, entre outros, Michel Foucault, ao retraçar a arqueologia das Ciências Humanas (Foucault: 1987).

É também contra o pano de fundo desse quadro que se deve entender a constituição da Sociologia francesa então nascente, e que dificilmente se distingue ainda da Etnologia, como mais comumente se designa a Antropologia nessa tradição, a não ser por uma inflexão quase imperceptível de enfoque, separando, por exemplo, Mauss de Durkheim, na ênfase diferencial dada por um ao fundamento simbólico da vida social, em oposição ao fundamento social do simbolismo, salientado pelo outro. O interessante, porém, é que, na sua origem, através de Durkheim, esta Sociologia julgue necessário afastar-se da História para constitutir-se como campo autônomo de saber, tomando por base o modelo organicista, próprio da Biologia, como metáfora de teoria e método capaz de dar conta da totalidade constituída pela vida social. Por outro lado, com relação à própria vida social, o problema durkheimiano é ainda o de Rousseau analista da Vontade Geral no Contrato Social ou o que, no projeto de Constituição da Polônia, salienta o papel das festas cívicas: qual o princípio que garante a coesão 
do todo social? A resposta de Durkheim é ainda a de Rousseau, lido porém, através de Kant, pela nova vertente socio-lógica que ele assim inaugura: transformando a sociedade em fonte do pensamento lógico, torna-se então possivel distinguir - e comparativamente demonstrar como se caracterizam -, em diferentes sociedades, sistemas classificatórios que constituem matrizes simbólicas diferenciais, graças às quais é possível compreender os diferentes modos de apreensão da totalidade que cada uma delas constitui. A metáfora biológica explica assim o enfoque funcional das instituições na economia do todo social, permitindo pôr em relevo os elementos que garantiriam a continuidade da sua forma de organização se, como explicitaria mais tarde Radcliffe-Brown, fosse possivel colocar entre parênteses os elementos que engendram a mudança, e que levariam à desorganização da estrutura, acarretando, no limite, a morte do organismo social.

Longe da História, o estrutural-funcionalismo salienta, assim, elementos que, em diálogo com a escola sociológica francesa, a História irá depois redescobrir, na idéia da longa duração. Em que pese o aparente paradoxo resultante desse diálogo, o importante é que esses primeiros historiadores da Escola dos Annales tinham consciência, como sociólogos e antropólogos, de que lidavam com totalidades cujas partes não permitiam o isolamento arbitrário. Assim, a história dos hábitos alimentares é impensável sem "o resto" da civilização material, da economia e do capitalismo, como demonstra Braudel, para enfatizar, no entanto, que também eles são impensáveis sem esse pequeno universo do quotidiano onde se dá a formação e consolidação de atitudes, valores, condutas que são a condição de sua manutenção, constituindo um universo de significados capaz de determinar a vida social em profundidade maior que as instituições políticas ou a administração do estado. É em relação a essa visão totalizadora que se compreende a necessidade de se desvendar simultaneamente e de modo inter-relacionado, como duas faces da mesma moeda, o universo onde se constrói o sentido da familiaridade tanto quanto as formas de legitimidade do poder político, passando pelas demais estruturas da vida social, como parecem concordar Duby ou le Goff, para se desvendar o que constituiria uma História da Vida Privada ou, o que desta perspectiva vem a dar no mesmo, uma História da Vida Quotidiana.

Várias ordens de questões se colocam, no entanto, para a História, a partir de uma tal perspectiva. Como recuperar, no interior da História, a noção de uma totalidade cuja constituição mesma, como objeto teórico, só se tornou possivel longe da história? Quais os critérios que permitem definir o recorte de uma tal totalidade e seu âmbito de abrangência? Como tratar de modo específico ou com alguma profundidade das diversas "partes" desses "todos" assim constituídos? Como definir seu modo de interação e algum princípio de causalidade que garanta, através do tempo, a sua coerência e continuidade, nas fronteiras de uma totalidade recortada no tempo e definida pela mudança que o próprio tempo faz emergir? Quero crer que este é um ponto de inflexão essencial para a historiografia francesa, onde o diálogo da Escola dos Annales com a Sociologia e a Etnologia francesas deverá ser, se não interrompido, pelo menos matizado, para dar lugar à incorporação de outros modelos estruturais de análise, de ênfase mais ou menos explicitamente evolutiva ou, de todo modo, 
desde o início aliados da História: respondendo à questão da causalidade, eles permitem, em contrapartida, definir com maior precisão a "totalidade" muito mais fluida das Ciências Humanas de inspiração durkheimiana, e assim determinar com certo rigor o corte no continuum do tempo histórico que the define as fronteiras e o perfil, bem como a lei de suas transformações.

De característica marcadamente social, diferindo apenas na ênfase dada às determinações econômicas ou políticas - a exemplo do marxismo em suas várias versões - são tais modelos que destacam algumas esferas da vida social como aquelas onde se determinam as leis de sua mudança, e assim permitem definir a totalidade do sistema histórico em que se integram, daí resultando duas conseqüências. De um lado, a possibilidade de decomposição do todo social em suas esferas constitutivas, dando origem a histórias "regionais" - econômica, da arte, social, da religião, politica, da literatura etc. - cujas interfaces podem ser iluminadas através da exploração de mediações em número suficiente para permitir a reconstituição dos vínculos entre essas esferas hierarquicamente distintas, segundo os mesmos princípios de organização e de transformação, ainda que segundo diferentes ritmos ou intensidades temporais e que dão lugar a fenômenos e processos de curta, média e longa duração. De, outro, o fato de que, consequentemente, são relegadas a um segundo plano - concebidas como temas "menores", quando não são pensadas, no plano da ideologia, como meros "reflexos" das grandes estruturas econômicas, sociais ou políticas - questões relativas a valores, sistemas de crença, práticas, hábitos, costumes, instituições, enfim, toda uma gama de fenômenos mais obscuros, fugidios ou menos espetaculares, que mais tarde, da Nova História à História das Mentalidades e à História Cultural, seriam redescobertos como objeto, tema e problema, recuperando-se assim para o campo da História exatamente essas dimensões da vida social que desde sempre constituíram o foco privilegiado da análise antropológica. Parece significativo, nesse sentido, que a análise da vida doméstica e do lugar da infância, manifestamente um desses temas "menores" até a emergência da Nova História, devesse ser tratada por Ariès como História Social da criança e da família, embora o progressivo processo de privatização ali descrito correspondesse a uma "revolução do sentimento e da afetividade", provocando reações que, "em cadeia (...) se estendiam a toda a sociedade, seu habitat, seu urbanismo" (apud Vainfas, p. 17), produzindo igualmente, poderíamos acrescentar, efeitos significativos no campo da vida econômica ou política, com a progressiva consolidação do individualismo que está na base tanto da concepção do trabalho na sociedade burguesa quanto da consolidação do Estado moderno.

Dessa perspectiva, parecem inteiramente pertinentes as observações de Vainfas quanto à proximidade entre o campo da História da Vida Privada e da História da Vida Quotidiana, apesar das divergências que, nesse terreno, distanciam as posições de Duby e Le Goff. Confunde-se o universo da vida privada com o quotidiano? Não, mas passa necessariamente por ele, e nisso Duby não tem razão, ao pretender estabelecer uma hierarquia de valor epistemológico entre um e outro campo. Entretanto, estaria a História da Vida Quotidiana, ao procurar "ressuscitar o passado, restituindo-the o sabor como se ali ainda estivéssemos", condenada a limitar-se a um simples inventário de curiosidades, como pretende Le Goff? Seguramente não, se lembrarmos que, ao se recompor o sistema de símbolos 
que organiza a construção do significado de uma experiência historicamente distante, o estranhamento provocado por uma cor local e um sabor inesperado efetivamente outros, e que no entanto impregnam com sua marca grandes ou pequenos eventos históricos, tal como apreendidos pelos homens que foram seus contemporâneos - pode fazer-nos atentar para o fato de que "o passado é um país estrangeiro", como nos sugere Michelle Perrot: "Autrefois, ailleurs". Isso nos põe em alerta contra a visão triunfalista de uma História que se colocaria sempre os mesmos problemas e cujas leis de movimento a ciência da História estaria sempre sob a injunção de captar. E tampouco a restituição da cor e do sabor do passado nos parecerá um exercício ocioso, se soubermos compreender, com espírito antropológico, que ela nunca poderá constituir mera somatória de curiosidades, já que estas representam indicios, por mais fragmentários que sejam, de um quadro mental, psicológico e social, que referencia a representação e a ação de agentes históricos determinados, permitindo-nos vislumbrar por um momento, e por sobre a distância do tempo, o sentido de sua experiência e o significado que devem ter atribuído à sua vivência da história. Daí que a designação de História das Mentalidades me pareça mais adequada, para captar esse tipo de fenômeno, que a nova versão atual da História Cultural porque, neste caso, se se retoma em certa versão o conceito clássico da Antropologia - cultura - corre-se o risco de instituí-lo como campo (menor, talvez) de mais uma História "regional", que se contrapõe às outras (grandes) histórias - econômica, social ou política. $O$ que assim se pode esquecer é que mesmo o significado da grande História é impossivel de ser apreendido fora dessa atmosfera que banha seus eventos, por ser parte indissociável da totalidade em que eles se integram, e que impregna em profundidade o sentido da experiência, do mais banal fragmento da vida quotidiana à participação no grande acontecimento que, mais tarde, se verificará ter sido registrado como verdadeiramente histórico...

Creio que, no mesmo sentido, vale o alerta de Duby de que não se deve confundir a História da Vida Privada com a história da casa, da cama, da intimidade e da sexualidade - as vicissitudes de uma História da relação entre indivíduos, em suma. Se essas dimensões são inseparáveis da vida privada e nela ganham a primazia que the conhecemos, é porque são parte de um tipo específico de sociedade, a nossa - moderna, ocidental e cristã. Pois é ali que, a partir do século XVI e até o XIX, a regulação dos costumes e a nova ênfase que passa a ser dada a certas virtudes - como parcimônia, constância, equidade, tolerância, por exemplo - vêm a integrar-se a um lento processo de constituição de um novo tipo de sociabilidade e novos padrões de organização da vida social, no interior dos quais se constróem desde o modelo burguês de vida privada ou de sexualidade até as normas de civilidade que vão confluir para a construção dos valores de igualdade e liberdade como características de todos os homens e sobre os quais se funda a legitimidade de um novo tipo de poder político. Sob a forma do estado, este poder se autonomiza enfim, desvinculando-se das amarras que o prendiam à ordem sobrenatural, à ordem da natureza e à ordem social desde a Grécia antiga até os tempos medievais, para criar, como sua contrapartida, a figura de uma sociedade civil, na grande cisão que enfim estabelece em definitivo a distância entre a esfera pública e a esfera privada da vida social. $O$ individualismo que marca o nosso tipo de sociedade, cultura e 
civilização não se compreende fora desse processo de privatização da família até reduzitla ao modelo nuclear que the conhecemos desde o século XIX, mas um olhar antropológico nos advertiria que a própria idéia de indivíduo e de familia nuclear carece de sentido fora do contexto de transformações que vão demarcar - novo lugar do sistema de parentesco nessa sociedade. Tais transformações passam pela ordem da natureza, através do domínio técnico que sobre ela então se instaura, inseparável ele próprio de sua dessacralização e da laicização do conhecimento, para permitir enfim, na ordem da organização social, que os homens se constituam enquanto indivíduos, autonomizando-se em relação à ordenação do sistema de parentesco que, em outras sociedades, funciona como linguagem polissêmica e omnipresente que possibilita a organização e expressão de relações e valores que em nossa sociedade são associados à esfera pública da vida social. Portanto, constituir a vida privada em objeto, tema, problema ou abordagem universalmente válidos é um projeto que só se justifica pelo seu fracasso e no que ele revela pelo seu avesso, ao permitir reconhecer que este recorte da vida social só é rigorosamente aplicável ao nosso tipo de sociedade, cuja especificidade assim se demarca, contrastivamente.

Entretanto, e ainda a contrapelo, tal projeto também aponta de forma oblíqua para um outro problema, o das formas históricas e sociais de existência do indivíduo, assim como da intimidade e da familiaridade tais como as define Duby, em outros tempos e em sociedades distintas da nossa. Em diálogo com uma análise antropológica mais cuidada, tal problema poderá ser então enfrentado em seus próprios termos - a exemplo do que faz Pierre Clastres ao analisar a solidão do caçador guaiaqui em seu canto noturno na floresta paraguaia (Clastres 1988: 71-891 - e não, como parece propor Duby, pelo viés de um único eixo analítico, - poder e a vida pública que a partir de uma certa forma de sua organização se instaura, e que só é capaz de apreender negativamente, como falha, ausência ou indistinção, uma esfera autônoma da vida privada em outros tempos e outras formas de organização da vida social. Creio que, mais uma vez, o que aqui se acha em jogo é a questão da definição da totalidade de que, tal como o antropólogo, deve ocupar-se o historiador voltado para essa outra História, ao mesmo tempo aquém e além dos grandes eixos clássicos da economia, das classes sociais ou da política: a invocação do poder, por parte de Duby, corresponderia talvez, neste caso, a uma nostalgia da grande eficácia dos modelos estruturais, que permitem encontrar um elemento unívoco de articulação para todas as histórias "regionais" em um determinado período ou sistema histórico, permitindo, pelo mesmo viés, uma varredura de longo alcance através do tempo, por meio da qual se teria condição de encontrar princípios universais e leis universalmente válidas, cujas variações caberia à ciência da História explicar. Creio ser este um dos pontos nodais do debate epistemológico sobre questões de método e paradigmas do conhecimento histórico para os quais aponta o texto do Prof. Vainfas.

De paradigmas e escalas

A Antropologia, como se viu, emerge tardiamente enquanto campo autônomo de saber, na segunda metade do século XIX, a partir de um diálogo 
com a História que se consubstancia no paradigma evolucionista característico dos seus primórdios. É a História que nos permite compreender, através do desenrolar do tempo, entendido como desenvolvimento do simples ao complexo, que o Homem é o mesmo em todas as latitudes, variando apenas o grau de sua evolução em direção ao que hoje conhecemos como o modelo mais avançado de sua civilização ou cultura. Assim se estabelecem simultaneamente a unidade do gênero humano e a diversidade das culturas, a conciliação da igualdade e da diferença que marca a constituição do campo da disciplina.

Em que pese o viés etnocêntrico que constitui a característica essencial do pensamento evolucionista e os mal-entendidos produzidos pelo projeto de reconstituição de uma História conjectural envolvendo todo o gênero humano, e que fez Durkheim voltar-the as costas na fundação da escola sociológica francesa, as lições da História nem por isso seriam perdidas. Crítico da visão evolucionista, Boas, um dos grandes pais fundadores da Antropologia que hoje conhecemos, redefine seu campo e perfil, ao contrário de Durkheim e seus discípulos, retomando o diálogo com a História, não como reconstituição de etapas de um hipotético desenvolvimento da humanidade, mas como descoberta de trajetórias reais de povos e grupos humanos determinados, no espaço e no tempo, e que constituem a sua história. É por este enfoque específico que sua teoria e método ficariam conhecidos como particularismo histórico, com base na tradição neokantiana que, de Windelband a Dilthey, distingue as "ciências nomotéticas" das "ciências idiográficas", entre as quais se distinguem as ciências propriamente históricas, fundadas no paradigma da compreensão, não da descoberta de leis. Em outra vertente, Lévi-Strauss, fiel à tradição durkheimiana que dialoga com a História através de Braudel, Lefebvre e Marc Bloch na Escola dos Annales, e que não só reivindica a herança desse diálogo como ainda se reclama da tradição boasiana, acabará sendo acusado de produzir uma Ciência do Homem sem sujeito e sem História... De onde se pode concluir que hesitações e oscilações na definição de um campo de saber e o verdadeiro qui pro quo epistemológico que delas resultam não é privilégio negativo da História, como se registra a propósito da constituição da História da Vida Privada, e, mais ainda, que esse debate no campo da História apenas revela pelo avesso os mesmos impasses nas Ciências do Homem com as quais ela dialoga.

Entretanto, o que está em jogo, pelo menos no caso da Antropologia, talvez não seja tanto um problema de paradigmas irreconciliáveis quanto um problema de escala: explicar o Homem contemplando a humanidade do ponto de vista de Sirius ou compreender a humanidade do Homem interpretando a sua expressão no mais infimo fragmento de sua conduta. Num e noutro caso, o desafio, para a Antropologia como para a História, é, ainda e sempre, recompor a totalidade. Nem mesmo Lévi-Strauss, na monumental orquestração das mitológicas, procurando fixar, com base no repertório americano, a lei de organização desse pensamento selvagem, que vê como princípio e o mais significativo exemplo do modo de funcionamento do próprio Espírito Humano, pode prescindir da história dos grupos cujos mitos analisa, para determinar o continente dos significados que são assim mobilizados de modo a compor o grande diálogo que, no plano das estruturas do inconsciente, permite que os mitos falem através de nós, e conversem entre si (Lévi-Strauss 1991; 1962; 1989). No polo oposto, Geertz 
leva às últimas consequências a historicidade que marca a própria produção do conhecimento no processo de interpretação das culturas, como texto que os atores sociais escrevem com sua conduta e que o antropólogo decifra por sobre seus ombros, ao tentar compreender o seu significado e o que uma cultura diz sobre si mesma ao explicitar-se como valor, regra ou marca de uma instituição no comportamento dos homens, em sua infinita variedade de expressões. E também ele tem razão: contar estórias sobre roubo de carneiros entre tribos berberes e mercadores judeus em território sob ocupação francesa no norte da África, é falar igualmente sobre "Poder, Mudança, Fé, Opressão, Trabalho, Paixão, Autoridade, Beleza, Violência, Amor, Prestígio", mas a partir de "contextos mais obscuros" lugares perdidos e vidas pequenas - "para retirar deles as maiúsculas": aqui, a "construção teórica não é codificar regularidades abstratas, mas tornar possíveis descrições minuciosas, não generalizar através dos casos, mas generalizar dentro deles" (Geertz 1978: 13-41).

No fundo, História e Antropologia são good neighbours, como afirma Robert Darnton (1990): os desafios são comuns e as trocas se intensificam através das fronteiras, muitas vezes ajudando a redefinir o campo, os temas e os problemas, o enfoque teórico e os procedimentos metodológicos entre as duas disciplinas. Assim, próximo à tradição historiográfica francesa, mas dialogando com outras vertentes antropológicas, Darnton analisa um massacre de gatos da Paris do século XVIII e nos fala da sociedade que verá surgir pouco depois a Grande Revolução; da mesma forma, Carlo Ginsburg empreende a imensíssima tarefa de decifração do sabá através da imagem do vôo noturno e reencontra Lévi-Strauss e algumas "estruturas elementares" do Espírito Humano /Ginsburg 19911; assim também Marshall Sahlins, percorrendo o mundo havaiano no rastro das aventuras do Capitão Cook, redescobre ithas de história, historicidades diferenciais onde se esperaria encontrar o puro triunfo da dominação ocidental ou povos sem história (Sahlins 1988).

Neste contexto, talvez ganhe novo significado a crítica acerba a que vem sendo submetida esta outra História que, das mentalidades à vida privada e à cultura, procura apreender, para além da pretensão de universalidade de que a ciência historiográfica francesa não parece capaz de se desatrelar, o lado obscuro de um mundo feito de pequenos eventos e pessoas comuns, indícios e sinais enigmáticos que de longe acenam em nossa direção e que nos convocam com paciência a decifrá-los, para aprender com eles que grande e variada é a trajetória do homem no tempo a que chamamos história. E não se diga que este entoque resulta apenas da perda de fôlego de uma ciência que renuncia aos seus propósitos pela nefasta influência da desagregação do conhecimento no mundo pós-moderno. O paradigma que sustenta esse empreendimento é antigo, como Boas nos permite constatar. Mas é sob o peso dos modelos estruturais que se torna necessário buscar leis, não compreender. E talvez coubesse perguntar se não será por isso que o tema do poder conhece hoje um tão grande prestígio, como denominador comum de tantas pesquisas históricas, erzatz dos grandes princípios estruturais que no passado permitiam tão facilmente determinar a lei de evolução das sociedades e da História. Do ponto de vista desses temas, apesar de tudo ainda "menores", de que se ocupa a História da Vida Privada, como antes a (velha) História das Mentalidades e agora a (nova) História Cultural, isso importa. 
Porque uma coisa é analisar a cultura pela ótica do poder, como faz, a exemplo da tradição sociológica que nas Ciências Sociais é retomada por Pierre Bourdieu (1992), também uma parte significativa da historiografia francesa que encontra similares igualmente na produção nacional. Outra coisa, porém, é entender 0 poder pela ótica da cultura, como fazem, na outra vertente do pensamento durkheimiano que a partir de Mauss deriva para uma tradição mais propriamente antropológica, um Pierre Clastres ou um Georges Balandier (1988). Resta saber se, libertos do imperativo da busca de leis, os historiadores franceses saberão recuperar essa tradição, em diálogo com o paradigma hermenêutico contemporâneo que também pode sustentar seu trabalho. E isto é essencial, porque, como conclui com razão o Prof. Vainfas, a escala de fato pode mudar nossa perspectiva de entendimento sobre uma História que, conhecida à saciedade nos seus grandes traços estruturais, parecia para sempre congelada na fixidez imutável do passado. Desse ponto de vista, recuperar um outro mapeamento dela através da História da Vida Privada é um empreendimento salutar, que já provou, na produção recente a que vem dando lugar, a legitimidade de seu campo de investigação, seus objetos, temas, problemas e abordagens. É de se esperar, portanto, que o aprofundamento do diálogo com as Ciências Sociais a que ela instiga possa vir a contribuir para 0 desenvolvimento de novas pesquisas nessa área, no campo da Antropologia, da Sociologia, assim como da História. 